\title{
The Influential Factors in the Medication Errors by the Nurses of the Internal Wards of the Teaching Hospitals Affiliated to Iran University of Medical Sciences (2019)
}

\author{
Ali Hosseinzadeh ${ }^{1}$, Daryadokht Masror $^{2}$, Hamid Haghani ${ }^{3}$
}

\begin{abstract}
Background \& Aims: Medication errors are common incidences in the nursing profession, which could lead to the increased length of hospital stay and treatment costs and occasionally severe damage to the patients or even mortality. The Many studies have investigated medication errors, with a few considering medication errors as a severe issue in the clinical setting. Other findings have confirmed that the cooperation of medical personnel and medical system could influence the rate of medication errors. Considering the essential role of nurses in all the steps of medication preparation to administration, limited studies have evaluated nurses' viewpoint regarding the influential factors in the incidences of medical malpractices, and mostly the viewpoints of emergency ward or ICU nurses have been investigated. The present study aimed to determine the influential factors in the medication errors by the nurses of the internal wards of the teaching hospitals affiliated to Iran University of Medical Sciences. Materials \& Methods: This descriptive study was conducted on 241 nurses employed in the internal wards of the teaching hospitals affiliated to Iran University of Medical Sciences in Tehran, Iran during June-September 2019. Data were collected using a demographic questionnaire and the questionnaire of nurses' views on medication errors designed by Bijani et al. (2013), which were completed by the nurses. Demographic data included age, gender, marital status, number of children, education level, interest in the nursing profession, nursing profession work experience (years), occupation status, working shift schedule, economic status, clinical workplace, workplace changes in recent months, and number of the off days in the past month. The questionnaire of nurses' views on the influential factors in medication errors has been developed by Bijani et al. (2013) with 22 items in three domains of the factors related to nurses in medication errors (11 items), factors related to the ward in medication errors (seven items), and factors related to the nursing management in medication errors (four items). The scoring system for each item is based on the significance of each factor on a four-point Likert scale (Very Low, Low, Moderate, and High), and each option is assigned a score within the range of 1-4, respectively. The mean score of each domain was calculated, with the low mean scores indicating the low significance of the domain in the incidence of medication errors and the high mean scores indicating the high significance of the domain in the viewpoint of the nurses. The questionnaire was completed by the nurses in a self-report manner and delivered to the researcher after one week. Data analysis was performed in SPSS version 16 using statistical tests. Results: According to the results, exhaustion due to heavy workload (mean score: $3.11 \pm 0.85$ ) was the most common cause of medication errors in the dimension of medication errors by nurses. In the dimension of hospital ward, heavy workload (mean score: $3.09 \pm 0.85$ ) was the most frequent cause of medication errors, and in the dimension of nursing management, the insufficient number of nurses in proportion to the number of patients (mean score: $3.53 \pm 0.61)$ was the most common cause of medication errors. In addition, the factor of nursing management (mean score: $2.77 \pm 0.51$ ) had the highest mean value, while the factor of ward (mean score: $2.55 \pm$ 0.54) had the lowest mean value among the influential factors in the incidence of medication errors in the viewpoint of the surveyed nurses. Lack of educational workshops (mean score: $2.3 \pm 0.81$ ) was the least significant cause of medication errors. The numerical indices of the influential factors in the incidence of medication errors
\end{abstract}

\footnotetext{
1. MS in Nursing, School of Nursing and Midwifery, Iran University of Medical Sciences, Tehran, Iran

2. Department of Nursing, School of Nursing and Midwifery, Iran University of Medical Sciences, Tehran, Iran (Corresponding author) Tel: $09123273135 \quad$ Email: masror.d@iums.ac.ir

3. Department of Biostatistics, School of Health, Iran University of Medical Sciences, Tehran, Iran
} 
in the domains of nurses, wards, and nursing management based on the demographic characteristics of the nurses indicated that only the number of children had a significant correlation with the incidence of medication errors $(\mathrm{P}=0.023)$, and the achieved mean score by the nurses without children was significantly lower compared to those with children $(\mathrm{P}=0.017)$. The incidence of medication errors in the domains of ward and nursing management had no significant correlations with the demographic characteristics of the nurses $(\mathrm{P}>0.05)$.

Conclusion: According to the results, the most significant influential factors in the incidence of medication errors in the viewpoint of the nurses were respectively nursing management, nurses, and the conditions of the internal wards. Therefore, it is suggested that to reduce the incidence of medication errors, the approaches to nursing management be revised. In addition, the implementation of educational workshops regarding medication errors could effectively decrease the incidence of medication errors by nurses, which should be considered by the authorities of educational centers. The incidence of medication errors could be reduced through academic education and by applying theoretical and practical courses during master's and bachelor's degree education. Regarding the related factors to the ward, it is recommended that the workload of nurses be decreased by increasing the nursing staff in proportion to patients, so that the working hours and working shifts of nurses could decrease to change their schedule, which could in turn minimize the incidence of medication errors.

\section{Keywords: Error, Medication Errors, Nurses, Internal Wards}

\section{Conflict of Interest: No}

How to Cite: Hosseinzadeh A, Masror D, Haghani H. The Influential Factors in the Medication Errors by the Nurses of the Internal Wards of the Teaching Hospitals Affiliated to Iran University of Medical Sciences (2019). Iran Journal of Nursing. 2020; 33(125):94-107.

Received: 18 May 2020

Accepted: 19 Aug 2020 


\title{
عوامل مرتبط با خطاهاى دارويى در بر ستاران بخشهاى داخلى مراكز آموزشى - درمانى دانشكاه علوم يزشكى ايران در سال
}

\author{
على حسين زاده '، در يادخت مسرور '، حميد حقانى
}

\begin{abstract}
جكيده

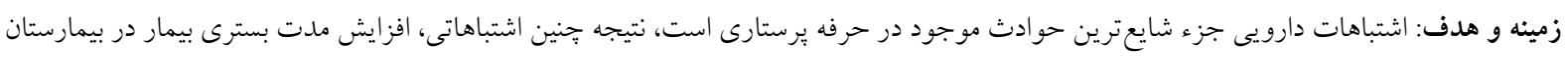

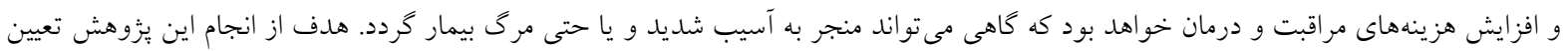

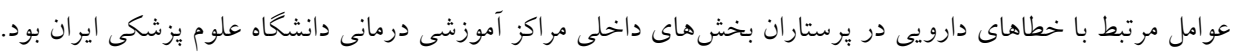

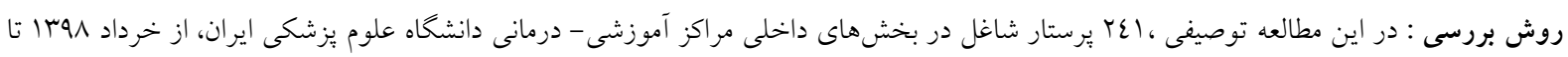

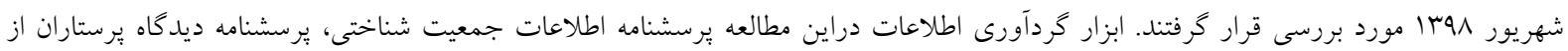

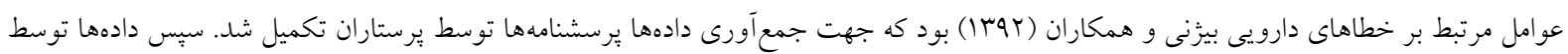

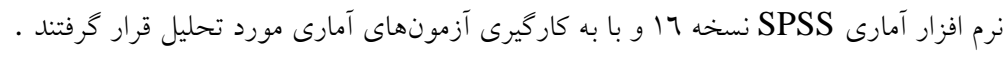

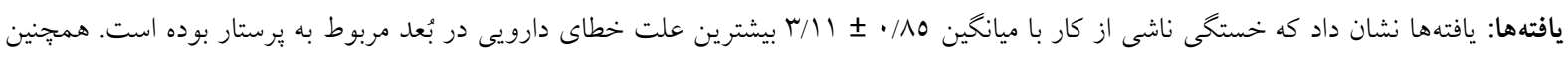

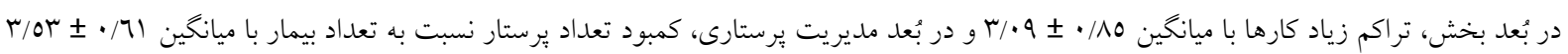

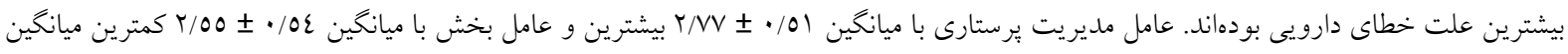

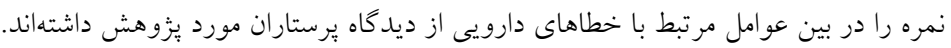

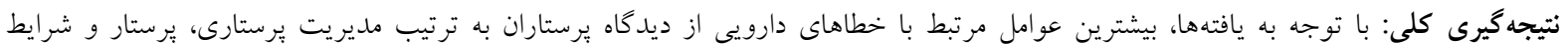

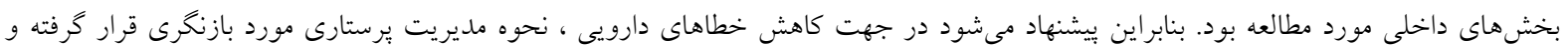

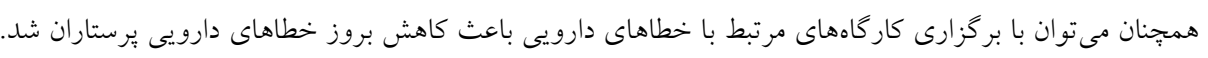

كليد وازمها: خطا، خطاهاى دارويى، برستاران، بخشهاى داخلى

تعارض منافع: ندارد

تاريخ دريافت: 99/T/Y9 تاريخ بذيرش: 99/0/T9

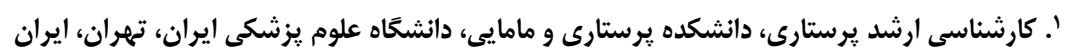

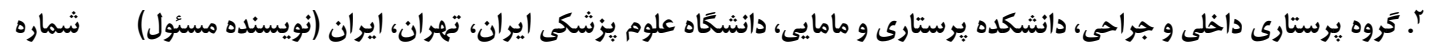

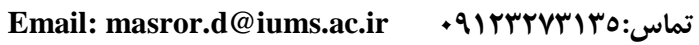

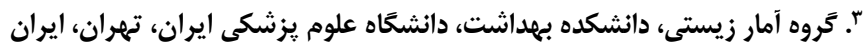


بيمـار، شرايط و وضعيت محيط بالينى، حجم كارى،

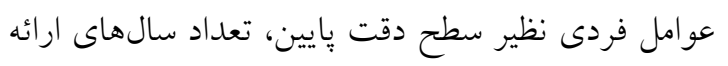

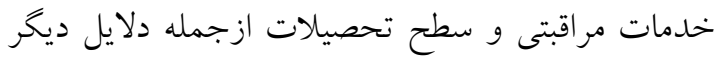

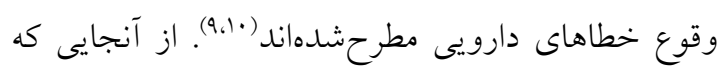

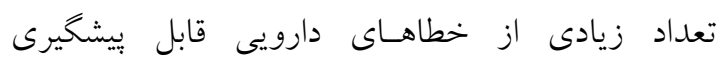

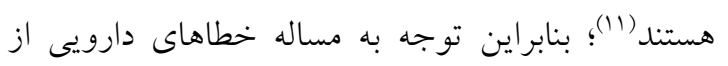

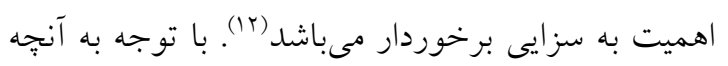

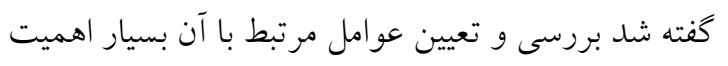

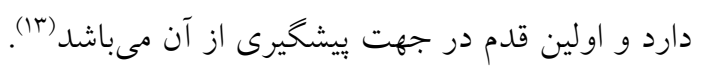

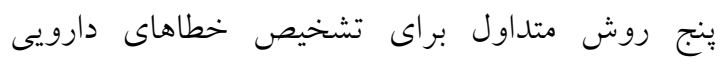

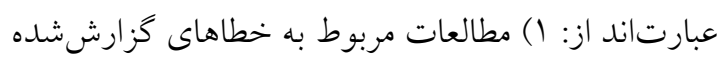

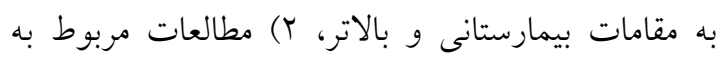

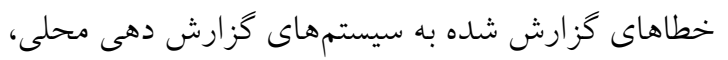

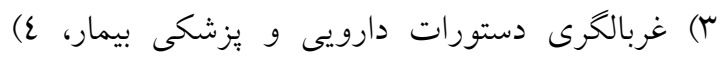
مطالعات مشاهدهاى و 0) مطالعات كيفى كه در آن با يرسنل مراقبتهاى بهداشتى مصاحبه شده است مى ولى

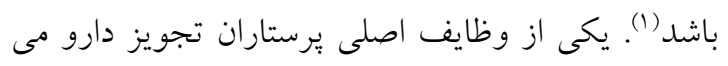

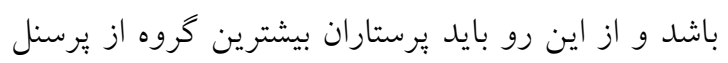

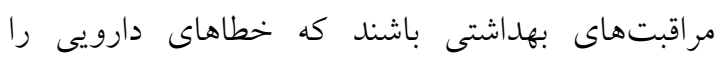

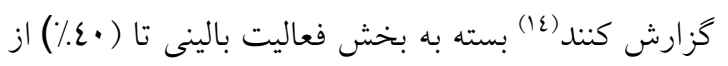

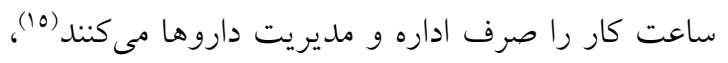

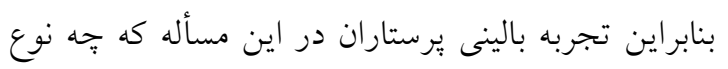

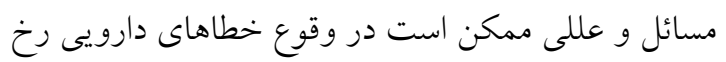

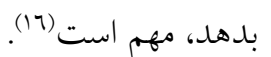

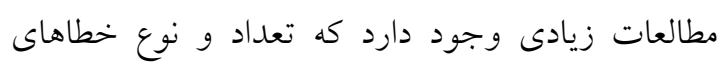

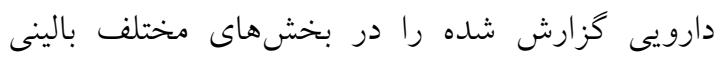
بررسى مى كند، اما تعداد كمى مطالعات با تمركز بر ديد كُاه

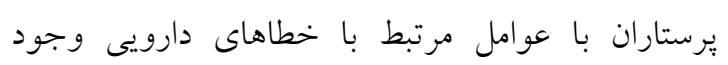

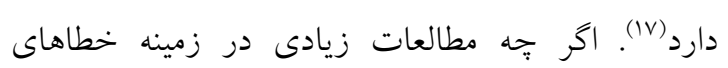

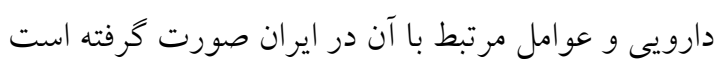

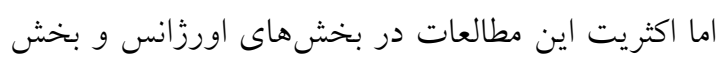

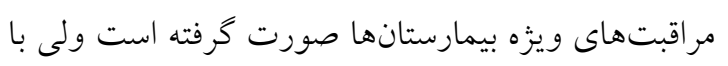
توجه به جست و جوهاى يزوهشخر ،به نظر مىرسد لازم

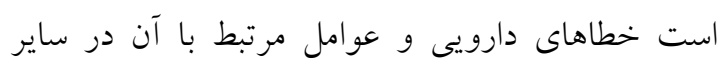


فاطمه (س)، حضرت على اصغر (ع)، شفا يحيائيان، شهيد

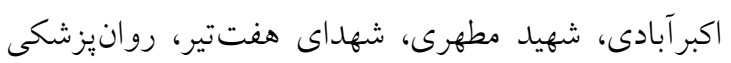

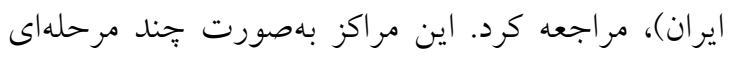

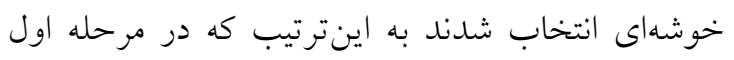
مر اكز درمانى به دو دسته عمومى و تخصصى تقسيم شدند

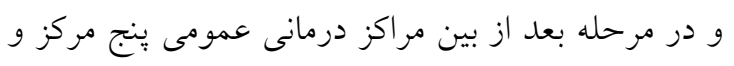

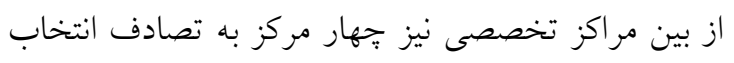

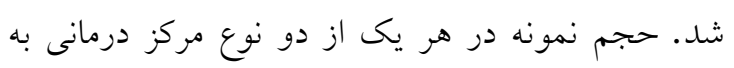

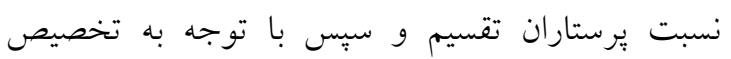
تصادفى در هر مركز درمانى از بين يرستاران نمونهها

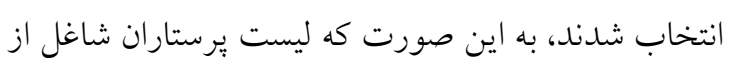

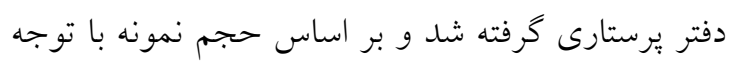

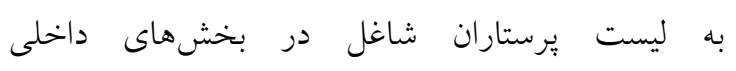

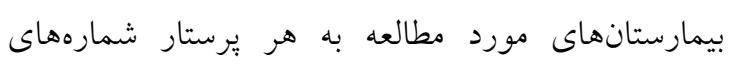

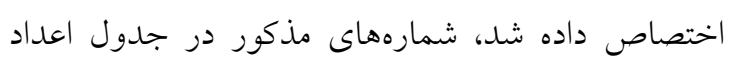

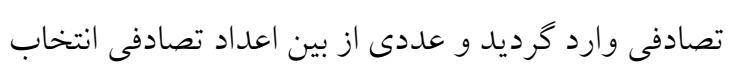

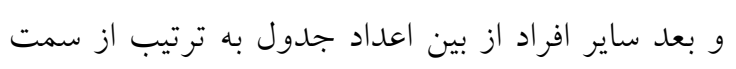

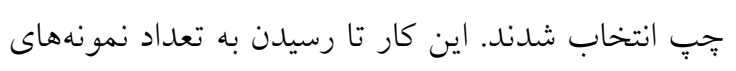
مورد نظر ادامه بيدا كرد. براى تعيين حجم نمونه لازم به منظور برآورد ميانخين نمره

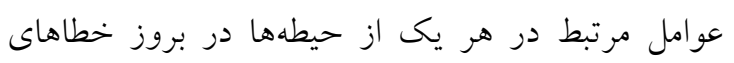

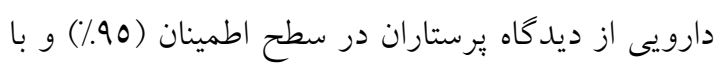

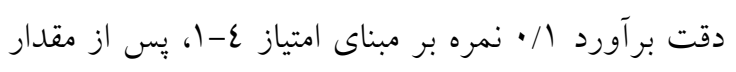

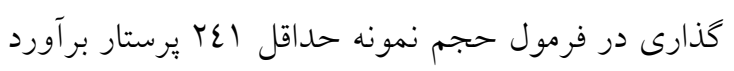

$$
\text { كرديد (جدول شماره ()). }
$$

بخشهاى بيمارستانها ازجمله بخش هاى داخلى صورت

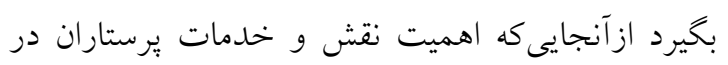

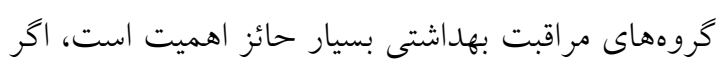
جه بيماران بسترى در بخشهاى مراى دانتلى بهلى بيمارستان،

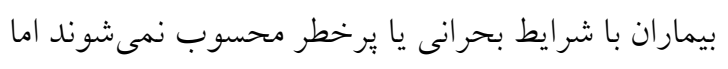

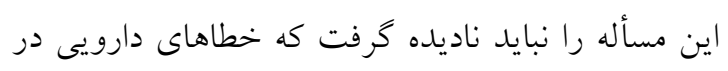
هر بخشى از بيمارستانها به وقوع مى بييوندد و هم:نينين

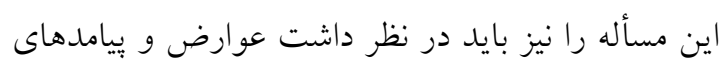

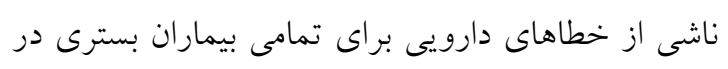

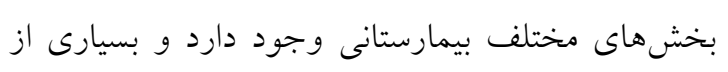

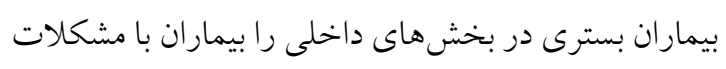

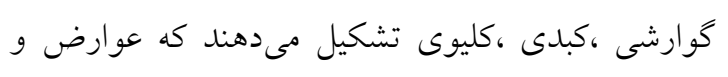

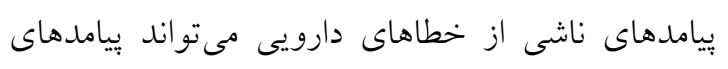

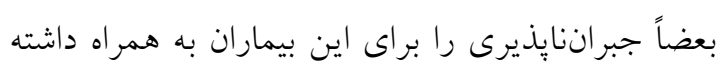

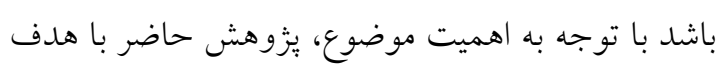
تعيين عوامل مرتبط با خطاهاى دارويى در يرستاران بخش هاى داخلى مراكز آموزشى - درمانى دانشخاه علوم

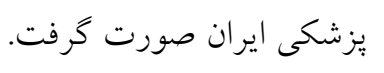

\section{روش بررسى}

براى انجام اين يزوهش كه يك مطالعه مقطعى از نوع

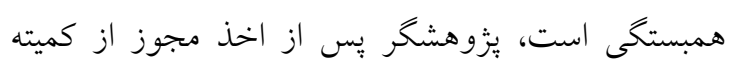

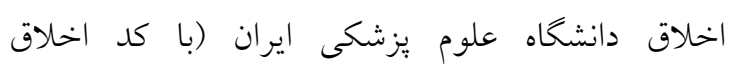

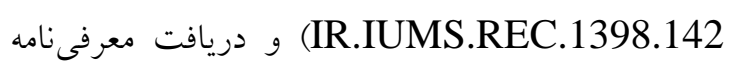
به مراكز آموزشى درمانى وابسته به دانشخاه علوم يزشكى وانى

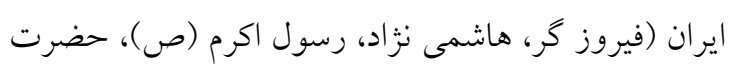

جدول شماره (: اسامى بيمار ستانها و توزيع فراوانى برستار ان شاغل در بخشهاى داخلى مراكز آموزشى درمانى دانشكاه علوم يزشكى

\begin{tabular}{|c|c|c|c|c|c|c|c|c|c|c|}
\hline & ايران & هفتم تير & & فاطمه & مطهرى & على اصغر & هاشمى نزاد & اكرم & & آموزشى درمانى \\
\hline TEl & ir & rq & 17 & 19 & $r \varepsilon$ & $T \varepsilon$ & $r$. & oq & $\varepsilon r$ & تعلداد يرستاران \\
\hline $1 .$. & $0 / r q$ & $\mid r / \cdot r$ & זר & $\mathrm{V} / \mathrm{MA}$ & $9 / 90$ & $9 / 90$ & $N / T q$ & $r T / \varepsilon$. & $I V / \varepsilon Y$ & درصد فراوانى \\
\hline
\end{tabular}

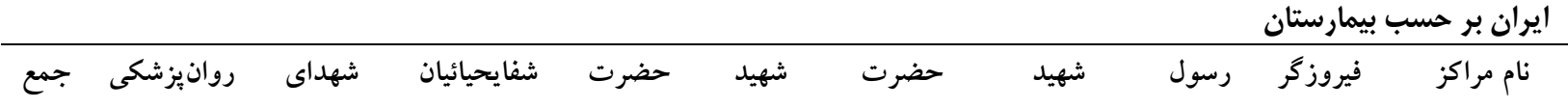


كرديد. اين يرسشنامه توسط بيزنى و همكاران در سال

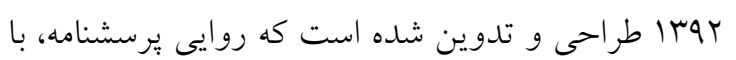

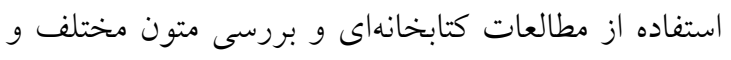
همجنين نظرخواهى از صاحبنظران و مشاوره با فعالان

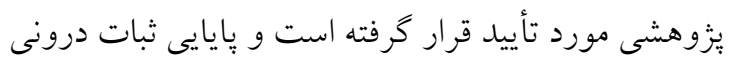

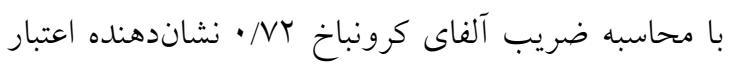

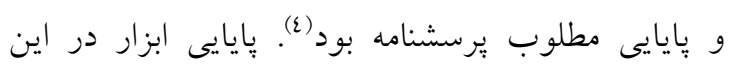

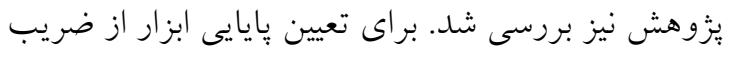

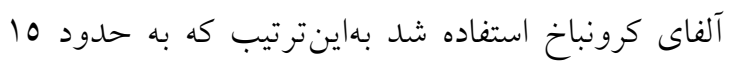

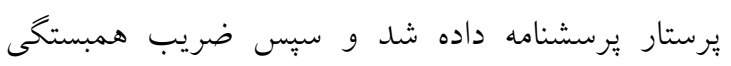

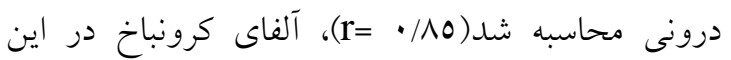
مطالعه ع/V/ بـه دست آمد.

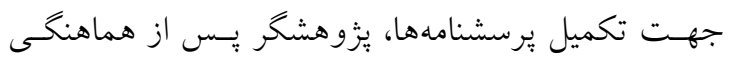
بـا سريرستاران، يرسششنامه را بيـن مشـاركت كنندكان

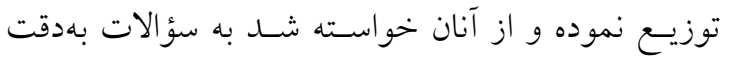
بِاسخ داده ؛ آنها را تكميل و تحويل يثزوهشكر نمايند.

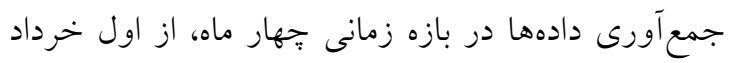

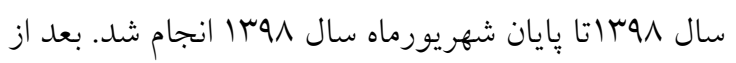

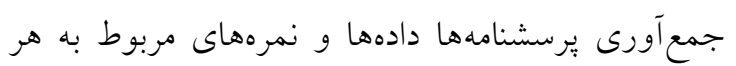

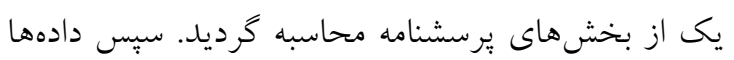

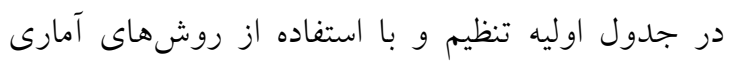

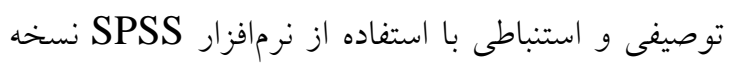

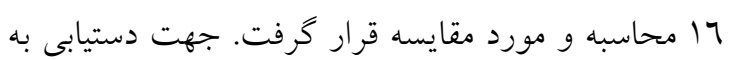
اهداف ويزٔه و وِاسخ دقيق به سؤالات تحقيق، از آمار

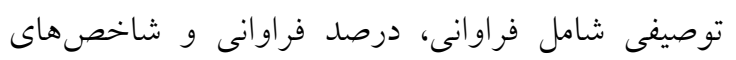

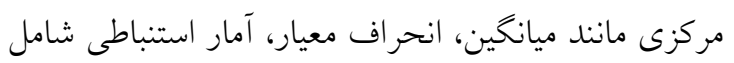

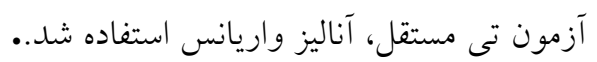

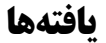

در اين مطالعه (حگr يرستار شاغل در بخشهاى داخلى بيمارستانهاى وابسته به دانشخاه علوم يزشكى ايران مورد مطالعه قرار كرفتند (همه نمونههاى مورد مطالعه، يرسشنامها را تكميل و تحويل يزووهشخر دادند). ميانخين

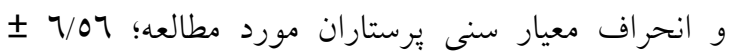

از هماهنكى با مترون بيمارستانها و كسب اجازه از

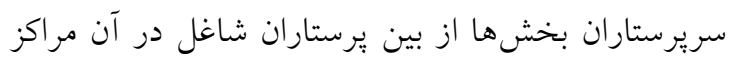

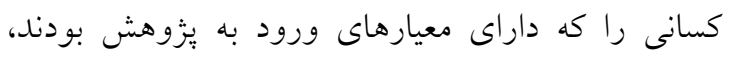

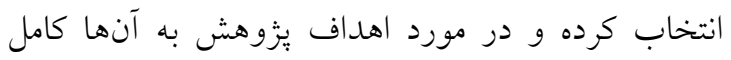

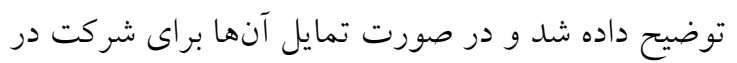

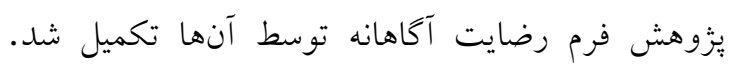

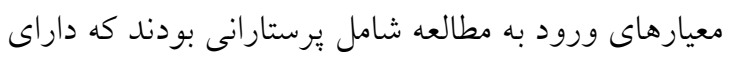

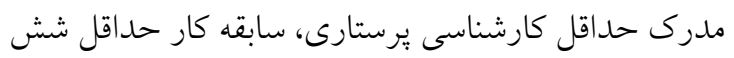
ماه، عدم شركت در دورههاى بازآموزى يا كاركاههاى

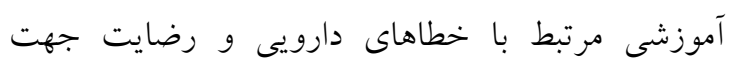
شركت در مطالعه بودند. فرم اطلاعات جمعيت شناختى برستاران حاوى اطلاعاتى مانند سن، جنسيت، وضعيت تأهل، تعداد فرزندان، سطح بطان

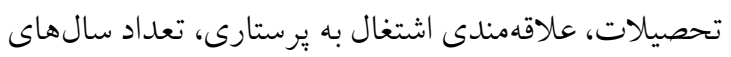

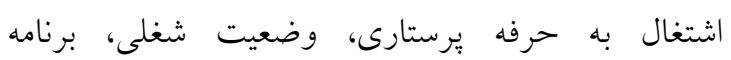
نوبت كارى، وضعيت اقتصادى، محل فعاليت بالينى، تغيير

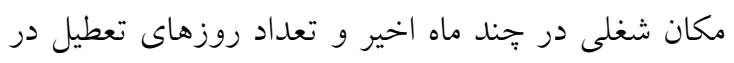

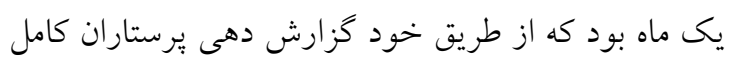
شد. برسشنامه عوامل مرتبط در بروز خطاهاى دارويى از بردئ

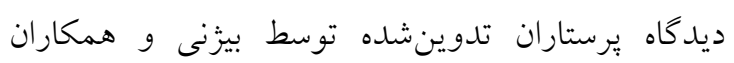

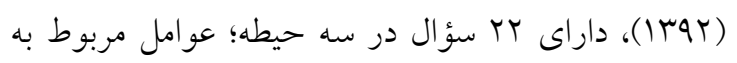
يرستار در بروز خطاهاى دارويى (11 سؤال)، عوامل

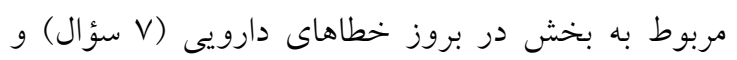

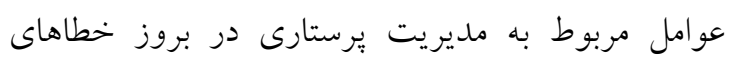

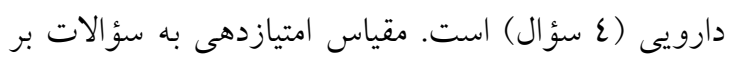

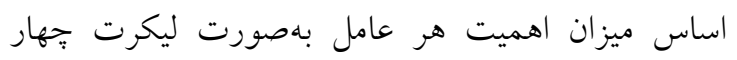

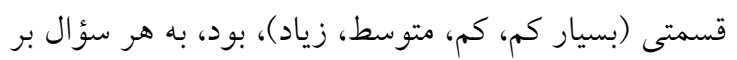

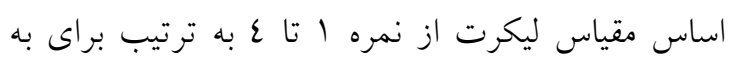

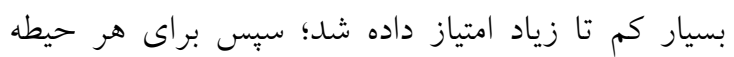

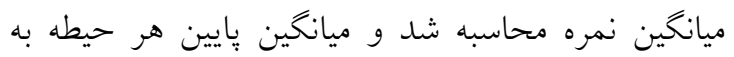
معنى اهميت كم حيطه در بروز خطاهاى دارويى و ميانخين بالاتر به معنى اهميت بيشتر آن حيطه در بروز خطاهاى

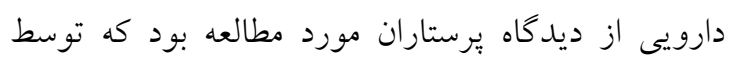

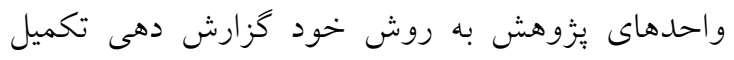


نفر (T/T/\%/) داراى سابقه بالينى 0-r سال بودند. اطلاعات جمعيت شناختى مربوط به يرستاران موردمطالعه در جدول شماره Y نمايش دادهشده است.

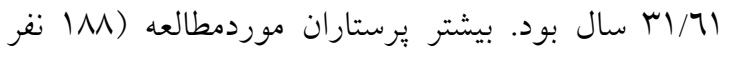

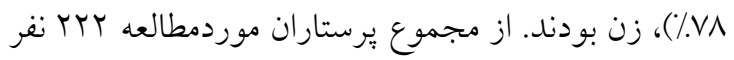

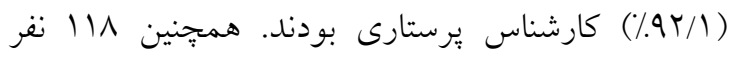

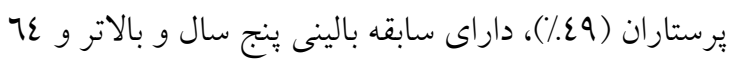

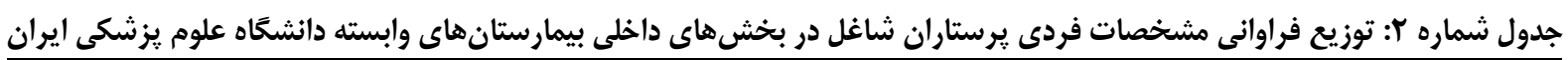

\begin{tabular}{|c|c|c|c|}
\hline درصد & 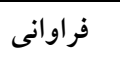 & مقادير & مشخصات \\
\hline$\varepsilon V / \Gamma$ & $11 \varepsilon$ & كمتر از ·•r & \\
\hline$\varepsilon \cdot / r$ & QV & $r \cdot-r q$ & سن (سال) \\
\hline $\mid r / \varepsilon$ & $r$. & •ع و بالاتر & \\
\hline VA & $1 M$ & زن & جنسيت \\
\hline rr & or & 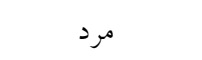 & \\
\hline$\varepsilon V / V Y$ & 110 & مجرد & وضعيت تأهل \\
\hline OT/RT & $1 K 7$ & 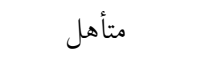 & \\
\hline$r Y / 00$ & $\varepsilon$ & بدون فرزند & \\
\hline rN/l1 & $\varepsilon \wedge$ & 1 & ت ت تعداد فرزند \\
\hline rT/Tr & r & r & \\
\hline$r / r l$ & $\varepsilon$ & r & \\
\hline $9 Y / 11$ & TYY & كارشناسى & تحصيلات \\
\hline$V / 9$ & 19 & كارشناسى ارشد & \\
\hline $91 / V$ & YYI & علاقهمند & علاقهمندى به اشتغال در يرستارى \\
\hline 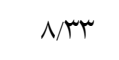 & $r \cdot$ & 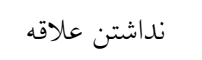 & \\
\hline$V / 9$. & 19 & ضعيف & \\
\hline$T V / T \cdot$ & $17 r$ & 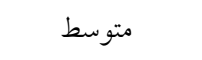 & وضعيت اقتصادى \\
\hline$r \varepsilon / 9$. & 7. & 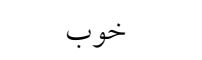 & \\
\hline$T \varepsilon \varepsilon / \varepsilon$ & 09 & $1-r$ & \\
\hline$r\urcorner \varepsilon / 7$ & $7 \varepsilon$ & $r-0$ & تعداد سالهاى اشتغال به حرفه يرستارى (سال) \\
\hline$\varepsilon 9$ & 111 & 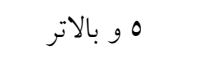 & \\
\hline $19 / 00$ & $\varepsilon \vee$ & نيروى طرحى & \\
\hline 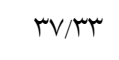 & 9. & 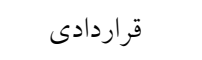 & 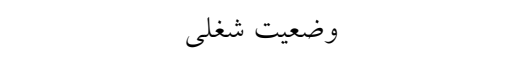 \\
\hline $1 \varepsilon / 9 \varepsilon$ & r & 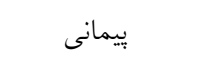 & \\
\hline TN/TO & $u$ & ل & \\
\hline N/vo & YI & صبح كار & \\
\hline V/07 & 11 & عصر كار & 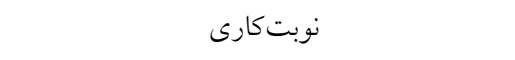 \\
\hline $1 \pi / \mu \varepsilon$ & rr & 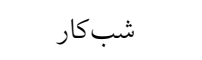 & \\
\hline$v \cdot 100$ & IV. & نوبت در گردش & \\
\hline $19 / 10$ & $\left.\sum\right\rceil$ & بله & تغيير مكان شغلى در جند ماه اخير \\
\hline $1 \cdot / 90$ & 190 & 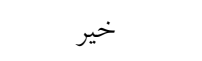 & \\
\hline r/vo & 9 & . & \\
\hline$\varepsilon \varepsilon$ & 1.7 & $1-r$ & تعداد روزهاى تعطيل در يك ماه \\
\hline OT/TO & IrT & ع و بيشتر & \\
\hline
\end{tabular}


خطاى دارويى و نوبت كارى صبح با ميانخين و انحراف

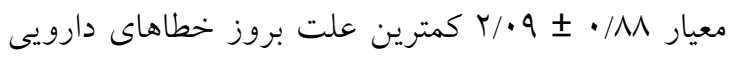
در بخشهاى دخلى بوده است (جدول شماره بَ).
مطابق با نتايج به دست آمده در مطالعه حاضر، در بعد

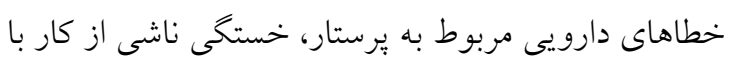

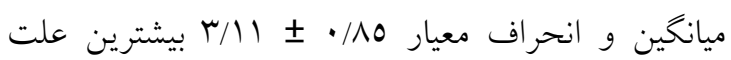

جدول شماره س: شاخصهاى عددى خطاهاى دارويى در بعد عوامل مربوط به يرستار

\begin{tabular}{|c|c|c|c|c|c|c|c|c|c|c|}
\hline \multicolumn{8}{|c|}{ برمبناى ليكرت } & \multirow{3}{*}{ انحراف } & \multirow[t]{3}{*}{ ميانغين } & \\
\hline \multicolumn{2}{|c|}{ زياد } & \multicolumn{2}{|c|}{ متوسط } & \multicolumn{2}{|c|}{ كم } & \multicolumn{2}{|c|}{ هيج } & & & \\
\hline درصد & فراوانى & درصد & فراوانى & درصد & 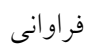 & درصد & 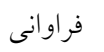 & & & \\
\hline$T \varepsilon / 0$ & 09 & $r_{\Lambda / \tau}$ & $9 r$ & Tr/T & $\wedge \cdot$ & $r / v$ & 9 & $\cdot / \wedge r$ & $r / \Lambda r$ & بىدقتى يرستار \\
\hline$r M / r$ & 01 & ron & $\wedge 7$ & $r \varepsilon / \varepsilon$ & $\wedge r$ & $\Lambda / V$ & rI & $\cdot / 9$ & $r / 79$ & فقدان انكيزه و بىميلى \\
\hline$r I / r$ & 01 & $r N / r$ & QY & rr & VV & $\Lambda / V$ & rI & $\cdot / 19$ & $r / V I$ & نَّاهيت نداشتن حرفه برستار \\
\hline $1 \varepsilon / 9$ & r & $r \Lambda / r$ & 94 & $r V / \Lambda$ & 91 & $9 / 1$ & rt & $\cdot / 10$ & $r / 01$ & مشكلات روحى روانى \\
\hline$r N / r$ & $u$ & $\varepsilon 1 / 1$ & 99 & $r \Upsilon / 7$ & $7 \varepsilon$ & $1 / 4$ & 1. & $\cdot / \wedge \varepsilon$ & $r / 9 r$ & نداشتن وقت و فرصت \\
\hline rq & $9 \varepsilon$ & $r V \mu$ & 9. & $19 / 9$ & $\varepsilon \wedge$ & $r / v$ & 9 & $\cdot / 10$ & $r / 1$ & خستكى ناشى از كار \\
\hline ror & 71 & $r T / \varepsilon$ & $\mathrm{v \wedge}$ & rV/A & 91 & $\varepsilon / 7$ & 11 & $\cdot / A V$ & $r / N \wedge$ & تازه كار بودن يرستار \\
\hline$V / 9$ & 19 & $19 / 9$ & $\varepsilon \wedge$ & $\varepsilon 0 / 7$ & 11. & $r 7 / 7$ & $7 \varepsilon$ & $\cdot / M$ & $r / .9$ & نوبت كارى صبح \\
\hline V/I & iv & $r V / \Lambda$ & TV & $\varepsilon \cdot N$ & 91 & $r \varepsilon / 0$ & 09 & $\cdot / 19$ & $Y / V I$ & نوبت كارى عصر \\
\hline ir & rq & $r y / 0$ & $\wedge$ & ron & $\wedge 7$ & $10 / 1$ & r & $\cdot / 19$ & $r / \varepsilon \varepsilon$ & نوبت كارى شب \\
\hline INN & ¿o & $r q / 9$ & vr & $\varepsilon r / T$ & $1 . \varepsilon$ & $\Lambda / r$ & r. & $\cdot / M$ & $r / 01$ & نا خوانا بودن كاردكس \\
\hline
\end{tabular}

نداشتن كارت دارويى با ميانخين و انحراف معيار 9 • •

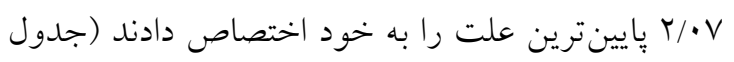

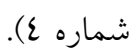

نتايج در بعد عوامل مربوط به بخش در بخشهاى داخلى

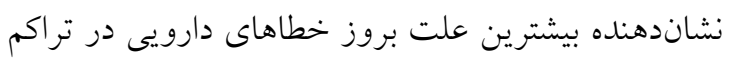

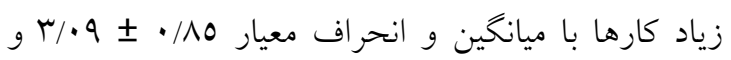

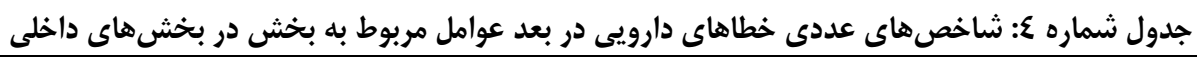

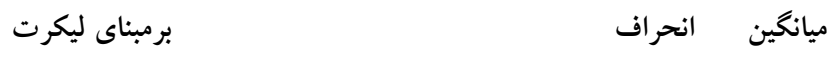

\begin{tabular}{|c|c|c|c|c|c|c|c|c|c|c|}
\hline \multicolumn{2}{|c|}{ زياد } & \multicolumn{2}{|c|}{ متوسط } & \multicolumn{2}{|c|}{ كم } & \multicolumn{2}{|c|}{ هيج } & \multirow[t]{2}{*}{ 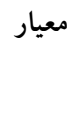 } & & \\
\hline درصد & فراوانى & درصد & 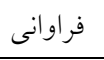 & درصد & 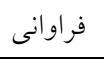 & درصد & فراوانى & & & \\
\hline $1 \varepsilon / 1$ & $r \varepsilon$ & $r \varepsilon$ & $\Delta r$ & $\varepsilon T / V$ & $1 . r$ & $9 / 1$ & rr & $\cdot / \wedge \varepsilon$ & r/or & سروصداى محيط بخش \\
\hline$\Lambda / r$ & r. & $r V / r$ & 9. & $\varepsilon r / 7$ & 1.0 & $1 \cdot / 1$ & rq & $\cdot / \mathrm{Na}$ & $r / \varepsilon r$ & فضاى اتاق (نور، فضاى فيزيكى) \\
\hline $\mid N / r$ & $\varepsilon \varepsilon$ & $r v / q$ & 19 & $r_{\varepsilon}$ & NT & $1 \cdot / 1$ & rq & $\cdot / 9$ & $r / T r$ & نوع بخش \\
\hline$\Gamma_{\Lambda / \tau}$ & qr & $r+/$ & $\wedge \vee$ & re & or & $r / \mu$ & $\wedge$ & $\cdot / 10$ & $r / .9$ & تراكم زياد كارها در بخش \\
\hline $19 / 1$ & $\varepsilon\rceil$ & rr/A & va & $r q / \varepsilon$ & 90 & $\Lambda / N$ & r & $\cdot / 19$ & $r / T r$ & نحوهجيدنداروهادرقفسه دارويى \\
\hline $\mathrm{V} / 0$ & 11 & rr & or & $\varepsilon \cdot / V$ & $9 \wedge$ & $r q / 9$ & Vr & $\cdot / 9$ & $r / \cdot V$ & 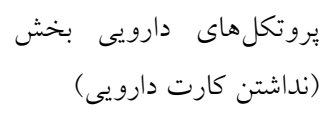 \\
\hline IN/V & ¿o & TV & 70 & $\sum 1 / 0$ & $1 \cdots$ & $1 Y / 9$ & $r_{1}$ &.$/ 9 \varepsilon$ & $r / 01$ & تشابه اسمى بيماران \\
\hline
\end{tabular}


خطاى دارويى و عدم برگزارى كارگاههاى آموزشى با

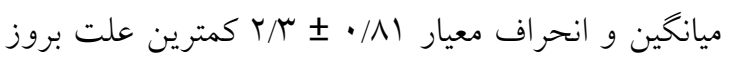
خطاهاى دارويى بودهاند (جدول شماره 0).
نتايج در بُعد عوامل مرتبط با مديريت يرستارى در بخش

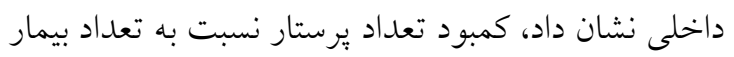

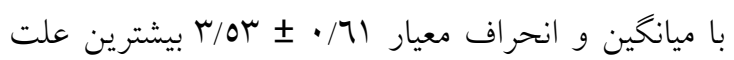

جدول شماره 0: شاخصهاى عددى خطاهاى دارويى در بعد عوامل مربوط به مديريت يرستارى در بخشهاى داخلى برمبناى ليكرت ميانكين انحراف دارويى دراف

\begin{tabular}{|c|c|c|c|c|c|c|c|c|c|c|}
\hline \multicolumn{2}{|c|}{ 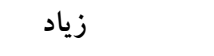 } & \multicolumn{2}{|c|}{ متوسط } & \multicolumn{2}{|c|}{ 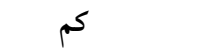 } & \multicolumn{2}{|c|}{ هيج } & \multirow[t]{2}{*}{ 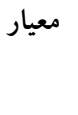 } & & \\
\hline ل درصد & 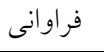 & مرصد & 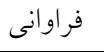 & درصد & 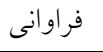 & درصد & 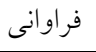 & & & \\
\hline $09 / 1$ & $1 \varepsilon \varepsilon$ & $\Gamma \mu / \tau$ & ᄉ1 & $7 / 7$ & 17 & . & . & $\cdot / 71$ & r/or & كمبود تعلداد يرستار نسبت به تعداد بيمار \\
\hline $1 \varepsilon / 9$ & m & $0 . / 7$ & ITr & $r \cdot / v$ & $v \varepsilon$ & $r / v$ & 9 & $\cdot / \sqrt{ } \varepsilon$ & YNT & شيوه نظارت و سريرستى بخش \\
\hline $10 / \varepsilon$ & rv & $r q / 9$ & vr & $\varepsilon 0 / 7$ & 11. & 9/1 & rt & $\cdot / 17$ & $r / 01$ & فقراى تزريق دارو امكانات و تجهيزات لازم \\
\hline$T / r$ & 10 & $r \varepsilon / \varepsilon$ & $\wedge r$ & $\varepsilon T / V$ & $1 . r$ & $17 / 7$ & $\varepsilon$. & $\cdot / \Lambda 1$ & $r / \mu$ & بركزار نشدن كار كاههاى آموزشى \\
\hline
\end{tabular}

ميانخين نمره كسب شده در برستاران بدون فرزند به طور

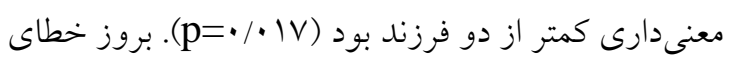
دارويى در بعد بخش و در بعد مديريت يرستارى با هيج

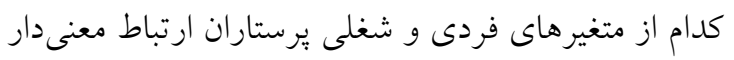

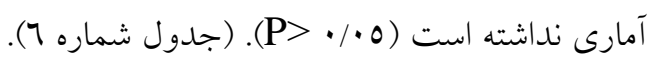

شاخص هاى عددى عوامل مرتبط بر بروز خطاهاى دارويى

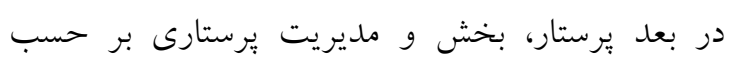

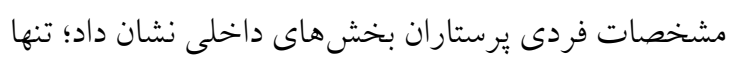

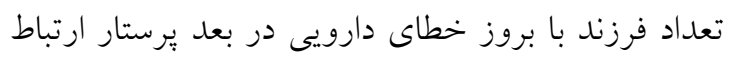

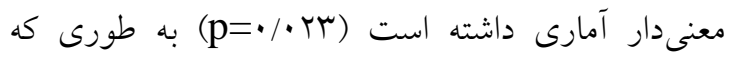

جدول شماره ا: شاخصهاى عددى عوامل مر تبط بر بروز خطاهاى دارويى برحسب مشخصات فردى يرستاران، بخش و مديريت برستارى بخش هاى داخلى

\begin{tabular}{|c|c|c|c|c|c|c|c|c|c|c|}
\hline \multicolumn{3}{|c|}{ بعد مربوط به مديريت برستارى } & \multicolumn{3}{|c|}{ بعد مربوط به بخش } & \multicolumn{3}{|c|}{ بعد مربوط به يرستار } & & \multirow[t]{3}{*}{ متغير هاى فردى } \\
\hline نتيجه آزمون & انحراف & ميانكين & نتيجه آزمون & انحراف & ميانكين & نتيجه آزمون & انحراف & 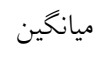 & & \\
\hline & معيار & & & معيار & & & معيار & & & \\
\hline$* t=1 / \varepsilon r \varepsilon$ & $r / .0$ & $11 / r$ & $* t=\cdot r \varepsilon 0$ & r/ar & IV/a & ${ }^{*} \mathrm{t}=\cdot / 09 \varepsilon$ & $0 / T V$ & $r q / \cdot V$ & زن ان & \\
\hline $\mathrm{df}=r \mathrm{rq}$ & $1 / 90$ & $1 . / 9 \varepsilon$ & $\mathrm{df}=r \mathrm{rq}$ & $r / \varepsilon \varepsilon$ & IV/NT & $d f=r m q$ & $\varepsilon / 79$ & $r N / 7$ & مرد & جنسيت \\
\hline $\mathrm{P}=\cdot / 10 \mathrm{r}$ & & & $\mathrm{P}=\cdot / N{ }^{\mu} I$ & & & $\mathrm{P}=\cdot 100 \mathrm{r}$ & & & & \\
\hline$* t=1 / \cdot r$ & $r / \mu$ & $11 / \pi r$ & $* \mathrm{t}=\cdot / \varepsilon V r$ & r/vı & IV/VV & $* t=\cdot / \varepsilon \cdot \varepsilon$ & $\varepsilon / 90$ & rA/Ar & مجرد & \\
\hline $\mathrm{df}=r \mu q$ & $r / .9$ & $11 \% \cdot 1$ & $\mathrm{df}=r \mathrm{rq}$ & $r / M$ & $1 N / \cdot 1$ & $d f=r r q$ & $0 / \pi r$ & $r q / 1$ & 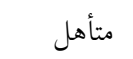 & وضعيت تأهل \\
\hline $\mathrm{P}=\cdot \mu \cdot \varepsilon$ & & & $\mathrm{P}=\cdot / 7 \pi \mathrm{V}$ & & & $\mathrm{P}=\cdot / \neg \mathrm{V} \vee$ & & & & \\
\hline$* * \mathrm{~F}=\cdot / \varepsilon 0 \varepsilon$ & $1 / \wedge r$ & $11 / \varepsilon V$ & $* * \mathrm{~F}=r / r \varepsilon r$ & $r / \varepsilon \varepsilon$ & $1 N / V$ & $\mathrm{~F}=\mathrm{r}^{\prime} / \mathrm{N} \mathrm{O}$ & $0 / \cdot 1$ & TV/Or & 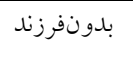 & \\
\hline $\mathrm{P}=\cdot / 7 \pi 7$ & $r / \cdot 1$ & $1 . / 9 \mathrm{~V}$ & $\mathrm{P}=\cdot / 111$ & $\varepsilon / r_{0}$ & $|v /|$ & $\mathrm{P}=\cdot / \cdot r \mu$ & $0 / .0$ & $r q / r_{0}$ & 1 & ت تعداد فرزند \\
\hline & $r / \bullet \wedge$ & $11 / \pi \varepsilon$ & & $r / \Lambda \varepsilon$ & $\mid N / 01$ & & O/AY & $r \cdot / 97$ & r & \\
\hline$* \mathrm{t}=\cdot /$ TrO & r & $11 / \varepsilon \wedge$ & $* \mathrm{t}=\cdot / .7$ & $r / v q$ & $1 V / \wedge 9$ & $* \mathrm{t}=1 /$ TYO & $0 / 11$ & 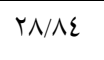 & كارشناسى & \\
\hline $\mathrm{df}=r \mu q$ & $r / r q$ & $11 / .7$ & $\mathrm{df}=r \mathrm{rq}$ & $\varepsilon / r V$ & IV/aq & $d f=r m q$ & $0 / \varepsilon r$ & $r \cdot / \varepsilon V$ & كارشناسى & تحصيلات \\
\hline $\mathrm{P}=\cdot / v \varepsilon 0$ & & & $\mathrm{P}=\cdot / 90 \mathrm{r}$ & & & $\mathrm{P}=\cdot / / \wedge\rceil$ & & & ارشد & \\
\hline & $1 / 97$ & $\| / T 1$ & & $r / \wedge \varepsilon$ & $1 V / 90$ & & $0 / 10$ & $r q / .7$ & علاقهمند & \\
\hline
\end{tabular}




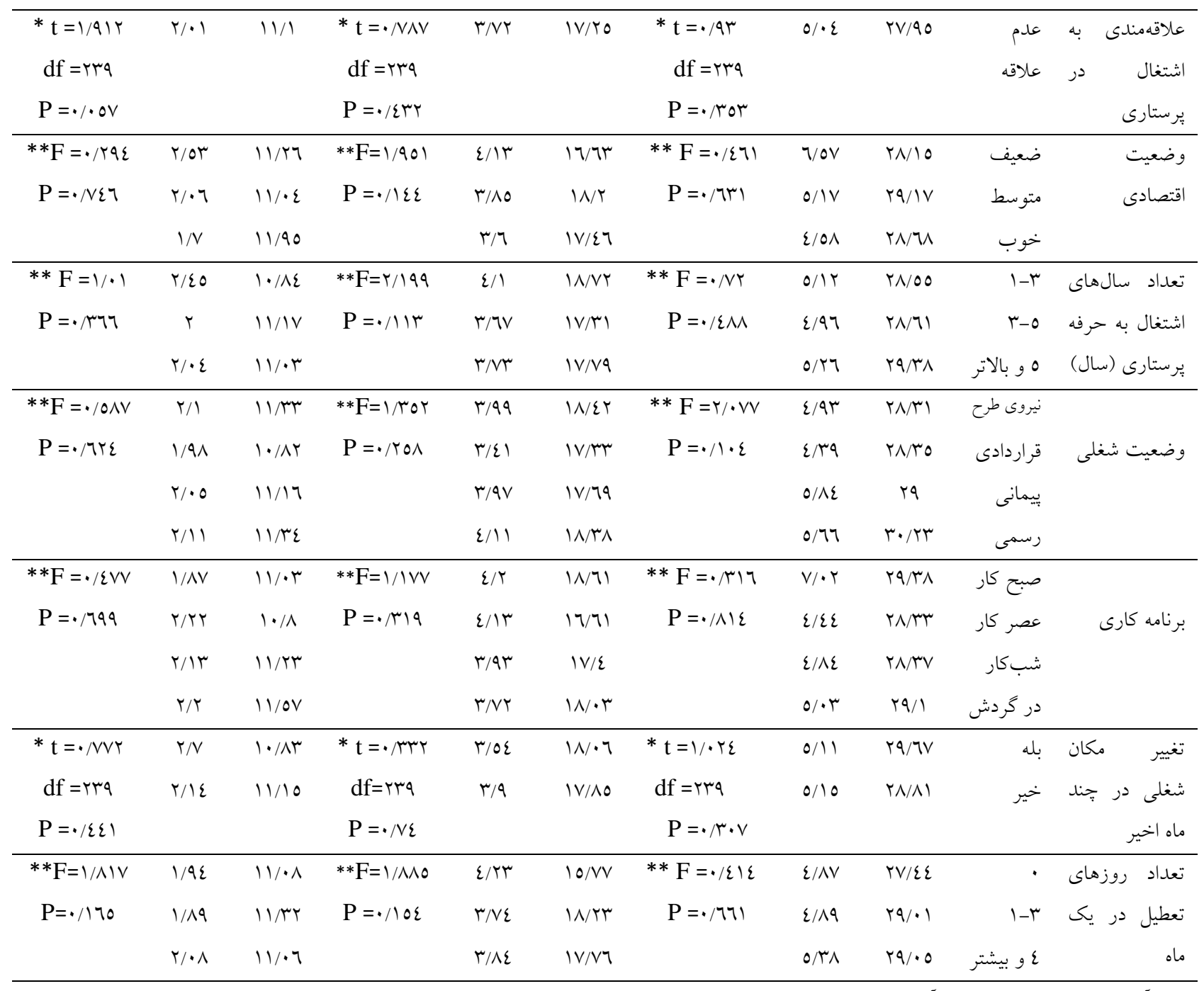

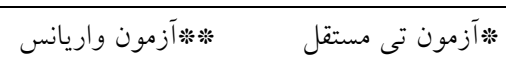

باشد از ديدكاه يرستاران با بروز خطاهاى دارويى همراه

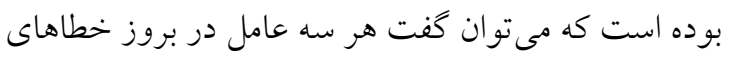

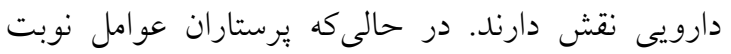

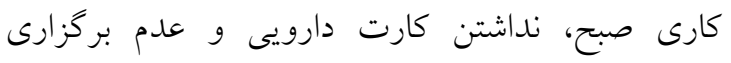
كاركاههاى آموزشى را به عنوان كمترين سهم در عوامل مرتبط با خطاهاى دارويى گزارش كردند. ضمن آنكه هيج

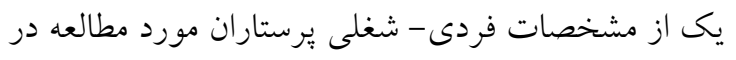

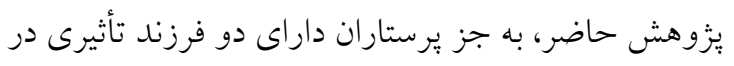

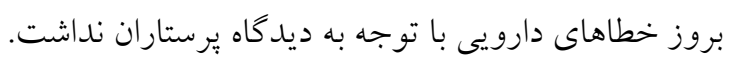

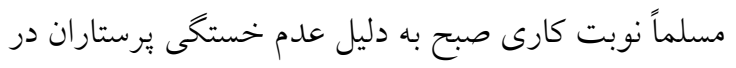

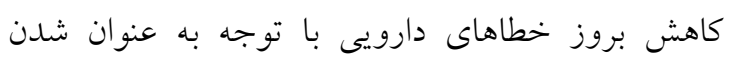

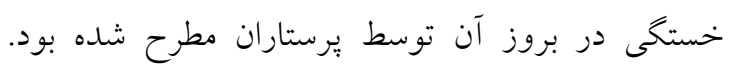

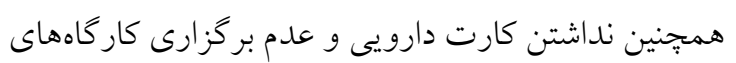

\section{بحث و نتيجه}

يُزوهش حاضر با هدف تعيين عوامل مرتبط با خطاهاى

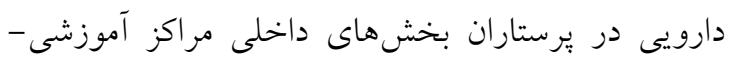
درمانى دانشخاه علوم يزشكى ايران صورت كرفت كه نتايج

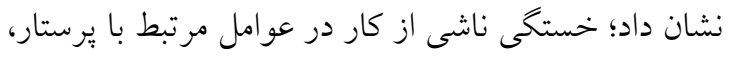

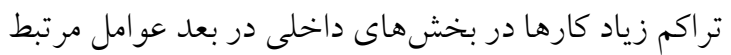

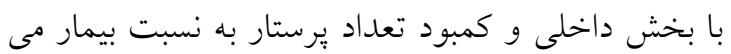

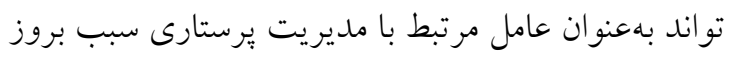

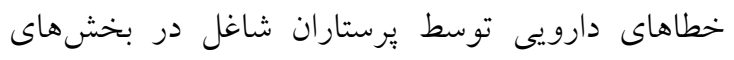

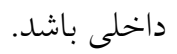
بنا بر نتايج مطالعه حاضر خستخى ناشى از كار برستاران

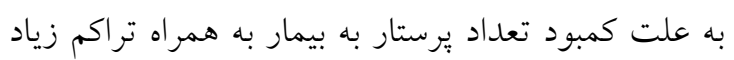

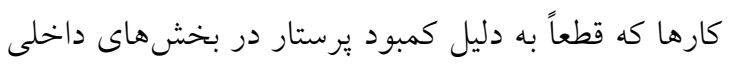


بررسى عوامل مؤثر بر بروز خطاهاى دارويى از ديدكاه

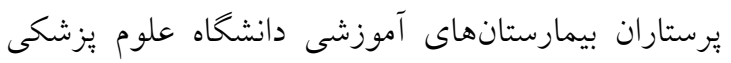
قزوين نشان داد خستخى ناشى از كار اضافى و نداشتن

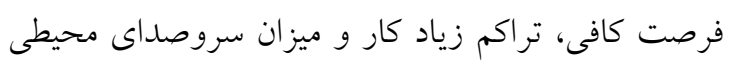

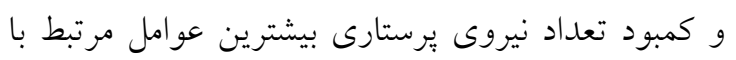

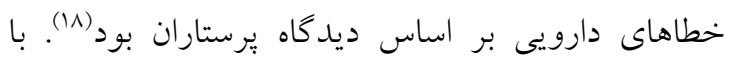

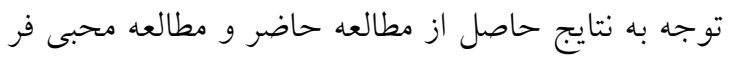

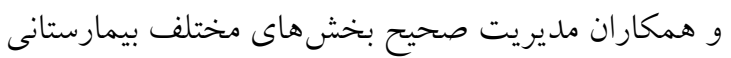

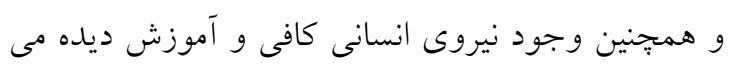

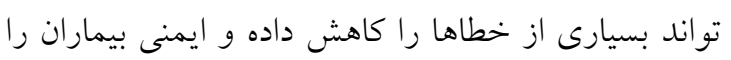
ارتقا دهد. - ماندا نتايج مطالعه حسين زاده و همكاران در بررسى علل

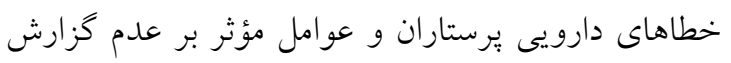

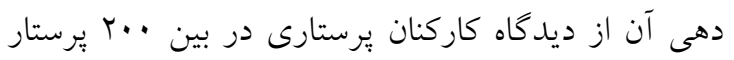

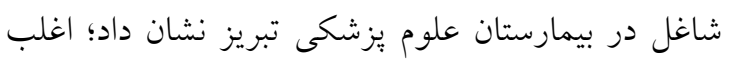

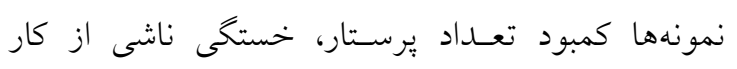

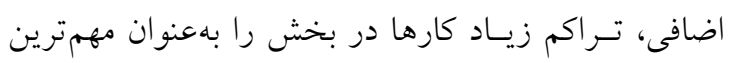

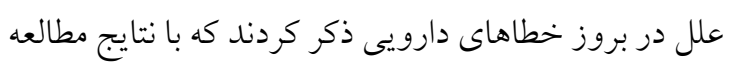

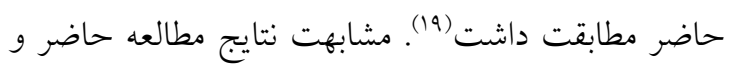

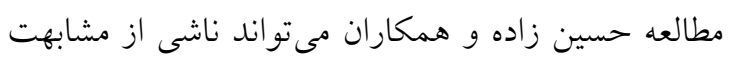

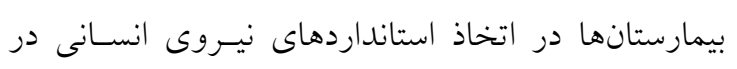

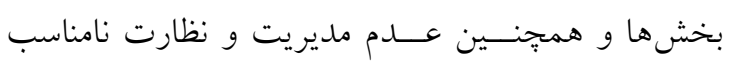
بر تقسيم و انجام وظايف باشد. نتايج مطان مالعه

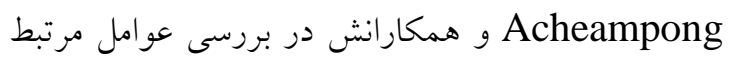

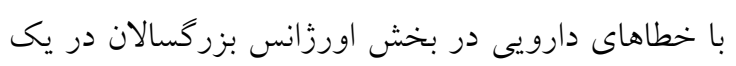

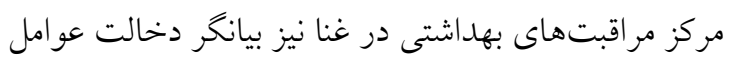

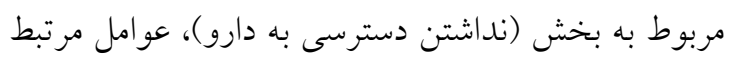

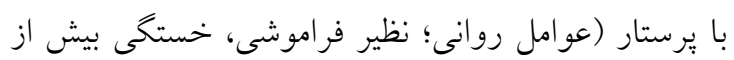

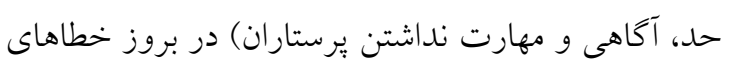

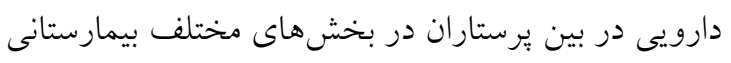

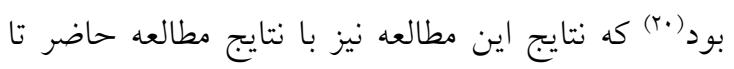

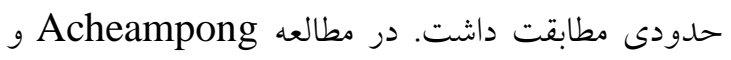

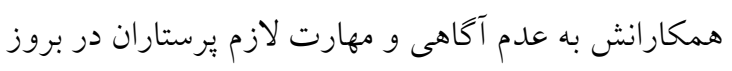

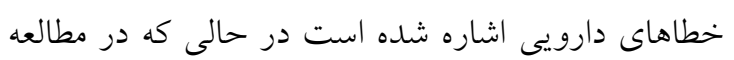

آموزش به عنوان كمترين عامل اثركذار در بروز خطاهاى

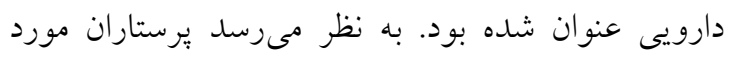

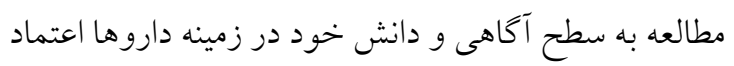
كامل دارند بهطورىكه تصور مى كنند حتى نداشتن كارت دارويى و يا عدم بركزارى كارگاههاى آموزشى از ديدكاه

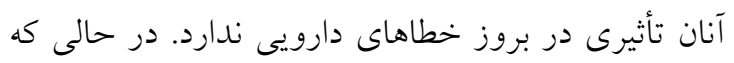
به نظر مىرسد عامل سطح دانش و آكاهى در زمينه داروها مى تواند در بروز خطاهاى دارويى نقش داشته باشند (1).). نتايج مطالعه بيزنى و همكارانش در تعيين عوامل تأثير كذار

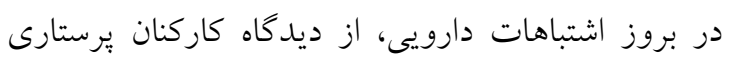
شاغل در بخش هاى مختلف بيمارستان وليعصر فسا نشان

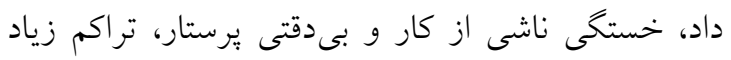
كارها در بخش و كمبود تعداد يُرستار نسبت به به بيمار

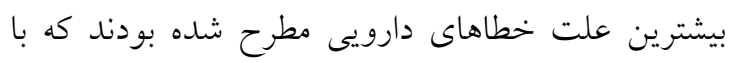
نتايج مطالعه حاضر مطابقت داشت (ع). يرستاران، بايد

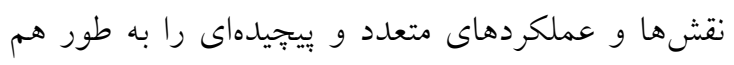

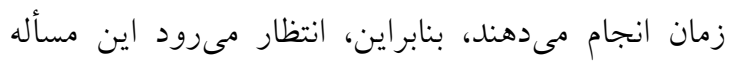

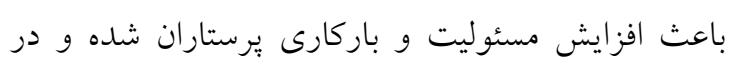

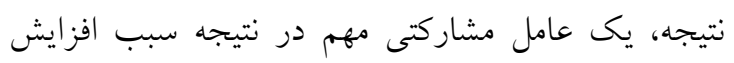

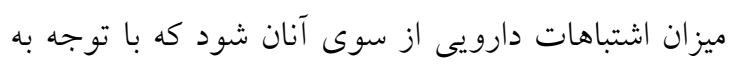
نتايج مطالعه حاضر و مطالعه بيزنى و همكاران عوامل

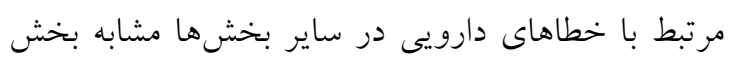
داخلى بوده است. نتايج مطالعه حبيبآبادى و همكاران در بررسى عوامل

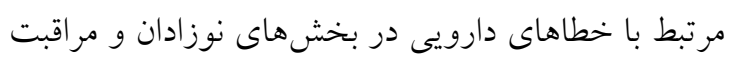

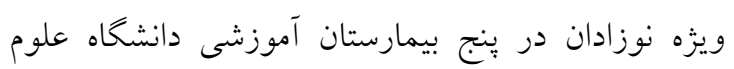

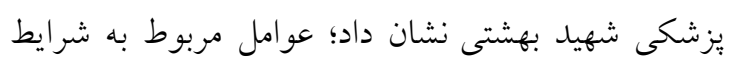

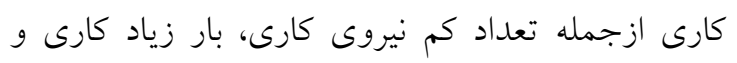

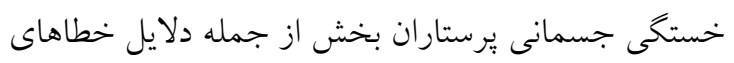

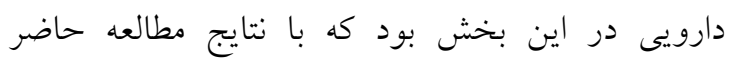

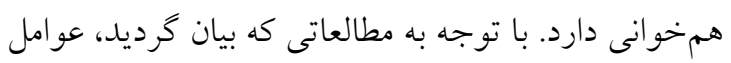

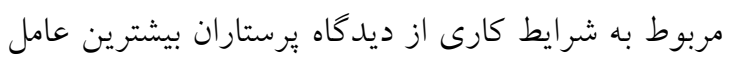

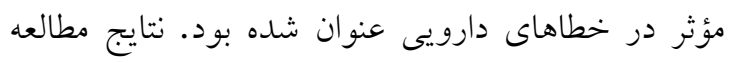

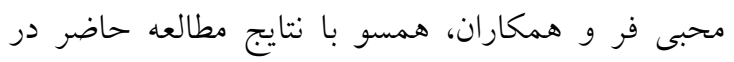


به نظر مىرسد بين هر سه عامل برستار، بخش و مديريت

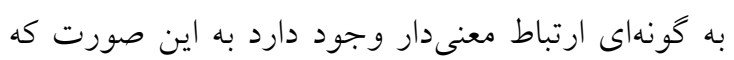

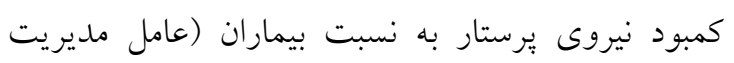

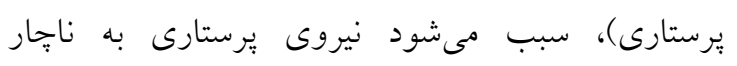

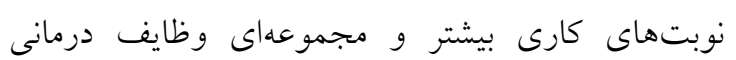

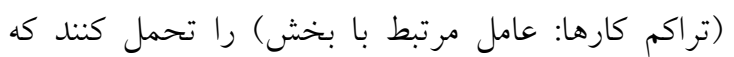

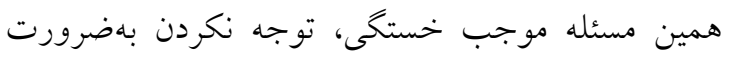

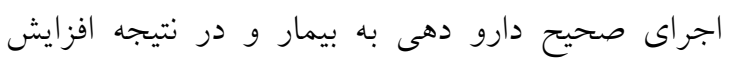

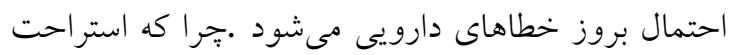

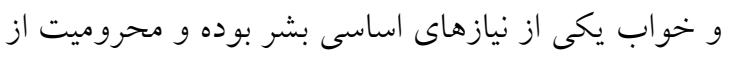

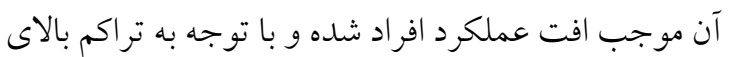

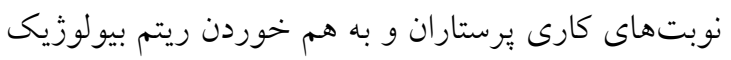

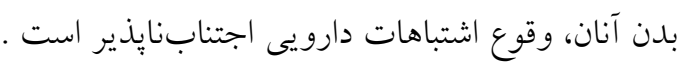

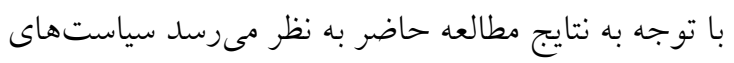

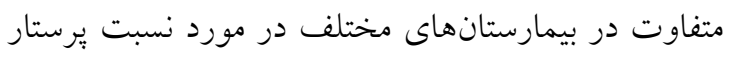

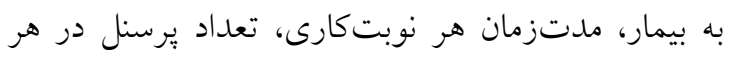

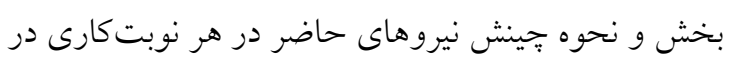

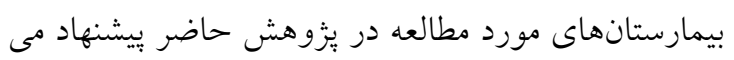

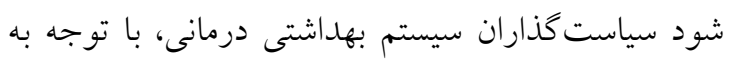
نقش حياتى و مهم يُرسنل برستارى در درمان و مراقبت از

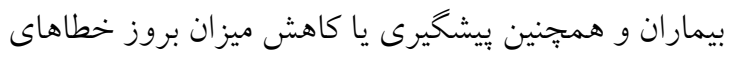

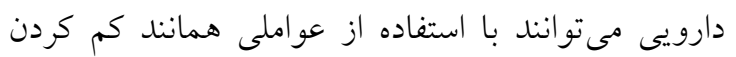
ساعات كارى، حذف نوبتهاى كارى متو الى اقدام نمايند.

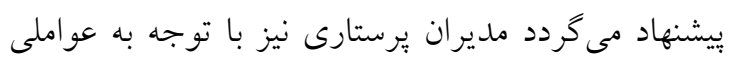

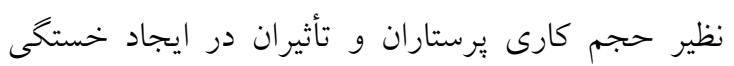

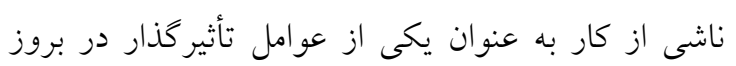

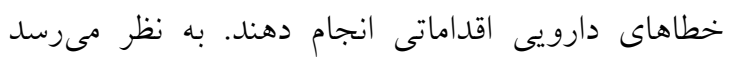

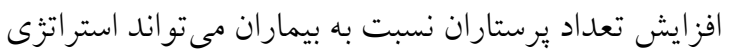
مناسبى در راستاى كاهش خستخى شغلى در بين برستاران

همانطور كه نتايج مطالعات مختلف نشان داد عدم آموزش مناسب در زمينه داروها و فقدان دانش در زمينه داروها

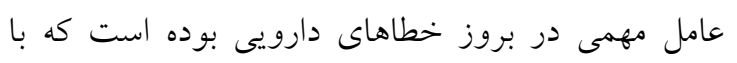

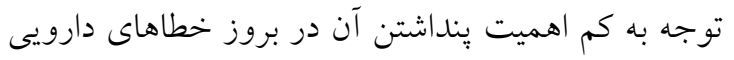

حاضر برستار ان عدم بركزارى كار گاههاى آموزشى در بروز

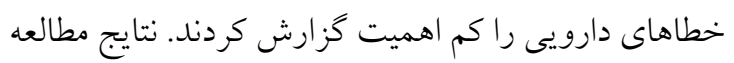
Alemu

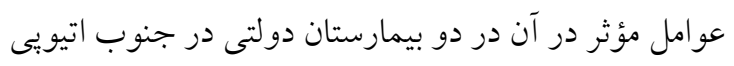

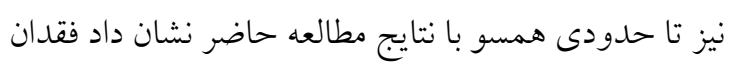

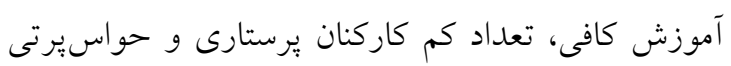
سه عامل اصلى در بروز اشتباهات دارويى در بين برستاران

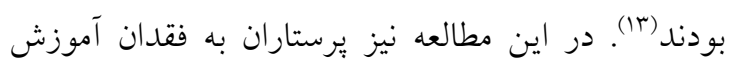

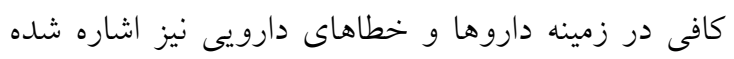

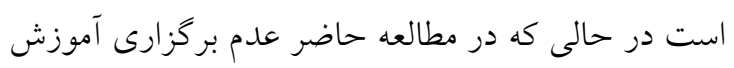

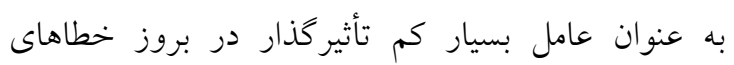

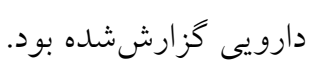

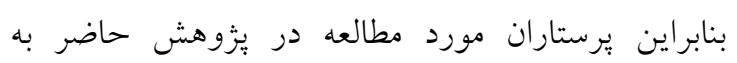

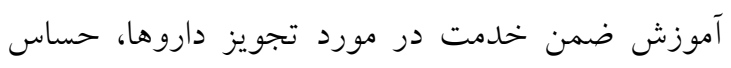

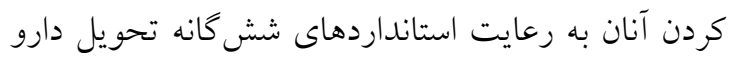

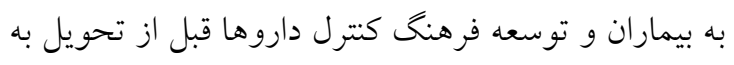

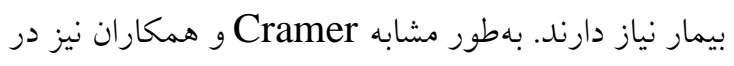

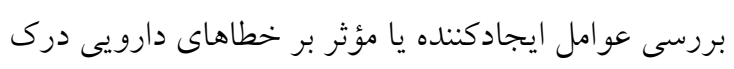

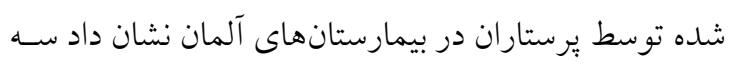
عامـل باركارى زياد، كمبود كاركنان و كار زياد مهمترين

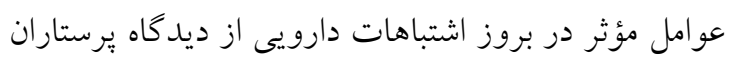

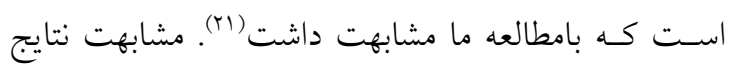

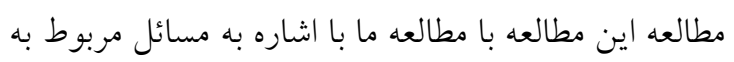

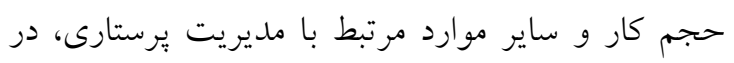

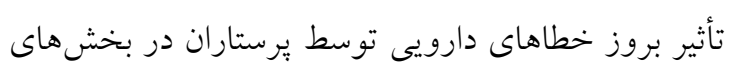
مختلف بيمارستانى يشتيبانى مى كنند. كه اين مسأله

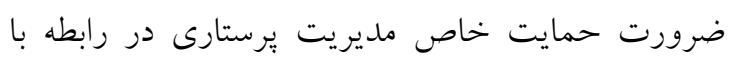

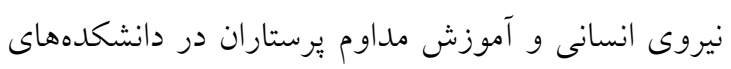
يرستارى و محيط بالينى و همجنين ارتقاء كيفيت مديريت

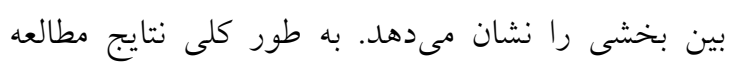

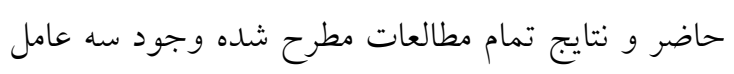

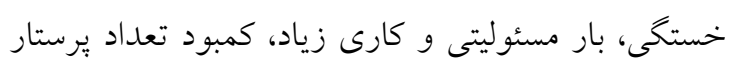

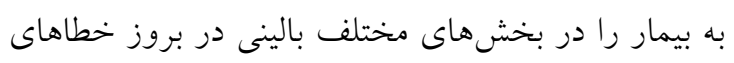
دارويى كزارش كرده بودند. 


$$
\begin{aligned}
& \text { افشا اطلاعات و عدم ذكر نام آنان در يرسشنامه شر ايط لازم } \\
& \text { را براى باسخ كويى صحيح به سؤالات را فراهم نمايد؛ اما }
\end{aligned}
$$

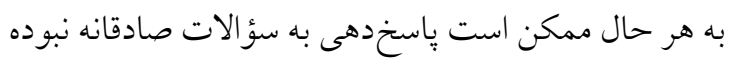

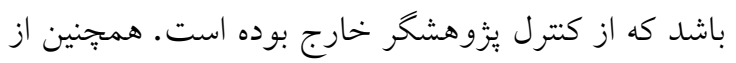

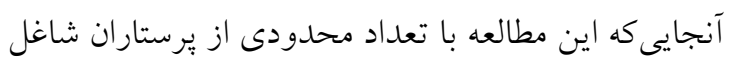

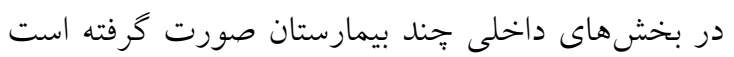

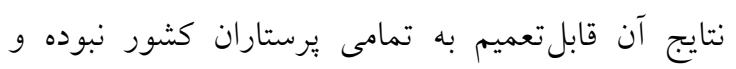

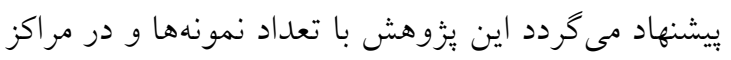

$$
\begin{aligned}
& \text { درمانى بيشترى در سطح ملى مجدداً انجام گيرد. }
\end{aligned}
$$$$
\text { بيان تعارض منافع: هيج كونه تعارض منافع توسط نويسند }
$$

\section{تقدير و تشكر}

اين مقاله حاصل باياننامه دوره كارشناسى ارشد يرستارى

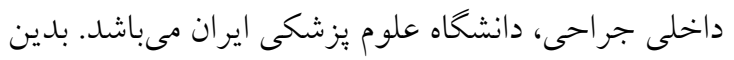

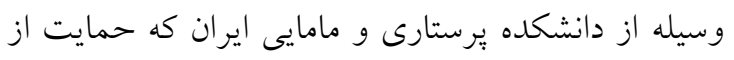

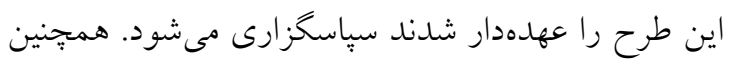

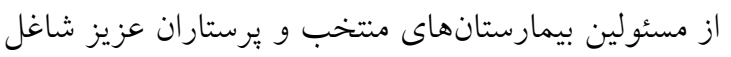
در بخشهاى داخلى كه با وجود مشغله هاى فراوان با ما در انجام اين يزوهش همكارى كردند صميمانه

$$
\text { سباسگز اريم. }
$$

از ديدكاه يرستاران مورد مطالعه در يزوهش حاضر لازم

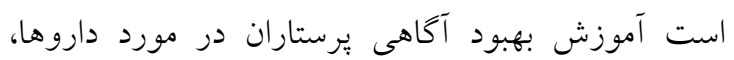

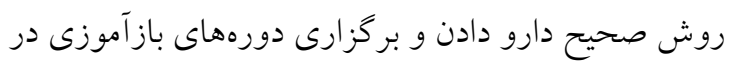
رابطه با تكنيكهاى اصولى تجويز داروها در يرستاران

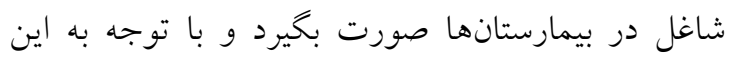

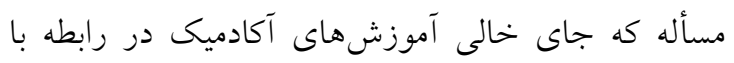

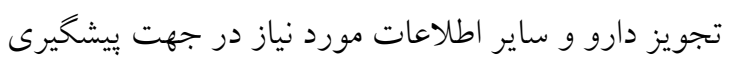

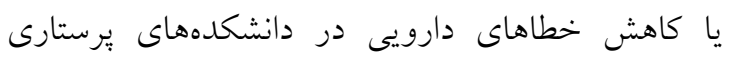

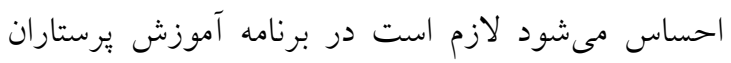

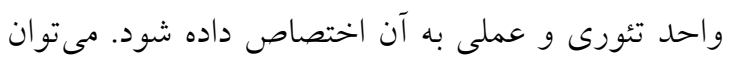

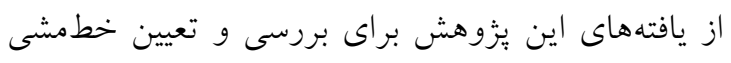

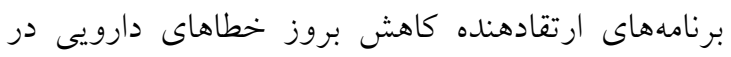
يرستاران شاغل در بخشهاى مختلف بهن بيمارستانى ازجمله

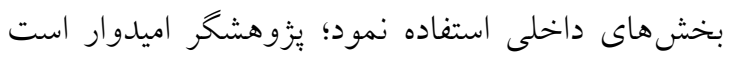

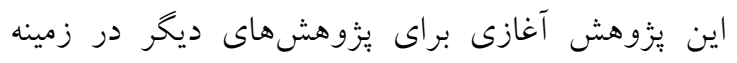

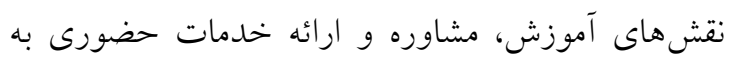

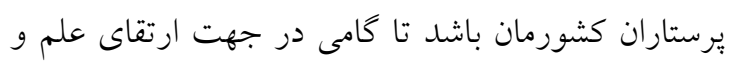
مهارت يرستارى برداشته شود.

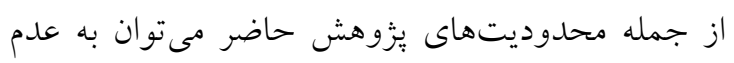

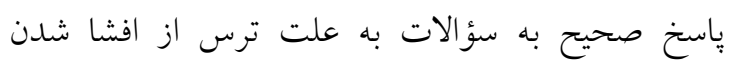

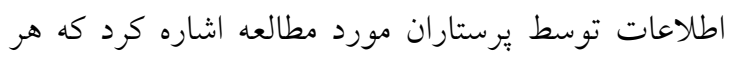

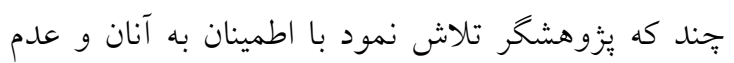

\section{References}

1. Abunahlah N, Elawaisi A, Velibeyoglu FM, Sancar M. Drug related problems identified by clinical pharmacist at the Internal Medicine Ward in Turkey. Int J Clin Phar. 2018;40(2):360-7.

2. Ehsani SR, Cheraghi MA, Nejati A, Salari A, Esmaeilpoor AH, Nejad EM. Medication errors of nurses in the emergency department. J Med Eth Hist Med. 2013;6.

3. Hajibabaee F, Joolaee S, Peyravi H, Haghani H. The relationship of medication errors among nurses with some organizational and demographic characteristics. Iranian Journal of Nursing Research. 2011 ,6(20): 8392. [Persian]

4. Bizhani M, Kouhpayeh SA, Abadi R, Tavacool Z. Effective factors on the Incidence of medication errors from the nursing staff perspective in various department of Fasa Hospital. Journal of Fasa University of Medical Sciences. 2013;3(1):88-93. [Persian]

5. Feleke SA, Mulatu MA, Yesmaw YS. Medication administration error: magnitude and associated factors among nurses in Ethiopia. BMC Nursing. 2015;14(1):53.

6. Hashemian F, Farzian M, Bakhshaei MH. Evaluation of prevalence, distribution and types of drug errors reported in Besat Medical Center of Hamadan during 2014-2015. Medical Science. 2019;29(3). [Persian]

7. Ahangar N, ALa S. Evaluation of Medication Errors in Internal Wards of Imam Sajjad Ramsar Hospital In 2017 Spring and Summer. medical journal of mashhad university of medical sciences. 2019;61(6):1314-22. [Persian]

8. Ribeiro GD, Silva RC, Ferreira MD, Silva GR. Slips, lapses and mistakes inthe use of equipment by nurses in an intensive care unit. Rev Escola Enferm USP. 2016;50(3):419-26. 
9. Ahangarzadeh Rezaei S, Baghaei R, Feizi A, Rahimi F. A survy on the nursing-related factors influencing medication error incidence. The Journal of Urmia Nursing and Midwifery Faculty. 2014;12(12):1088-93. [Persian]

10. Rothschild JM, Churchill W, Erickson A, Munz K, Schuur JD, Salzberg CA, Lewinski D, Shane R, Aazami R, Patka J, Jaggers R. Medication errors recovered by emergency department pharmacists. Annals Emerg Med. 2010;55(6):513-21.

11. BaloochiBeydokhti. T, Mohamadpour A, shabab S, nakhaee H. Cause of occurence and Barriers of Report of Medication Errors among Nursing Personnel of Gonabad Hospitals. Horizon Med Sci 2014;19(5):41-7. [Persian]

12. Alijanzadeh M, Mohebifar R, Azadmanesh Y, Faraji M. The frequency of medication errors and factors influencing the lack of reporting medication errors in nursing at teaching hospital of Qazvin University of Medical Sciences, 2012. Journal of Health. 2015;6(2):169-79. [Persian]

13. Alemu W, Belachew T, Yimam I. Medication administration errors and contributing factors: A cross sectional study in two public hospitals in Southern Ethiopia. Int J Afr Nurs Sci. 2017;7:68-74.

14. Björkstén KS, Bergqvist M, Andersén-Karlsson E, Benson L, Ulfvarson J. Medication errors as malpracticea qualitative content analysis of 585 medication errors by nurses in Sweden. BMC health services research. 2016;16(1):431.

15. Pham JC, Story JL, Hicks RW, Shore AD, Morlock LL, Cheung DS, Kelen GD, Pronovost PJ. National study on the frequency, types, causes, and consequences of voluntarily reported emergency department medication errors. J Emerg Med. 2011;40(5):485-92.

16. Davis L, Ware R, McCann D, Keogh S, Watson K. Evaluation of contextual influences on the medication administration practice of paediatric nurses. J Adv Nurs. 2009;65(6):1293-9.

17. Ahangar N, ALa S. Evaluation of Medication Errors in Internal Wards of Imam Sajjad Ramsar Hospital In 2017 Spring and Summer. medical journal of mashhad university of medical sciences. 2019;61(6):1314-22. [Persian]

18. Mohebbifar R, Bay V, Alijanzadeh M, Asefzadeh S, Mohammadi N. Factors influencing the incidence of medication errors: the perspective of nurses in teaching hospitals. Payesh (Health Monitor). 2015;14(4):43542. [Persian]

19. Hosseinzadeh M, Aghajari PE, Mahdavi N. Reasons of nurses' medication errors and persepectives of nurses on barriers of error reporting. Hayat. 2012;18(2):66-75. [Persian]

20. Acheampong F, Tetteh AR, Anto BP. Medication administration errors in an adult emergency department of a tertiary health care facility in Ghana. J Patient Saf. 2016;12(4):223-8.

21. Cramer H, Pohlabeln H, Habermann M. Factors causing or influencing nursing errors as perceived by nurses: findings of a cross-sectional study in German nursing homes and hospitals. J Pub Health. 2013;21(2):14553. 